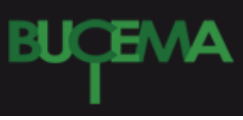

Bulletin du centre d'études médiévales d'Auxerre | BUCEMA

Hors-série $n^{\circ} 7 \mid 2013$

Les nouveaux horizons de l'ecclésiologie : du discours clérical à la science du social

\title{
Socialiser la foi. Une esquisse de parcours ecclésial
}

Dominique logna-Prat

\section{(2) OpenEdition}

1 Journals

Édition électronique

URL : https://journals.openedition.org/cem/13140

DOI : $10.4000 /$ cem. 13140

ISSN : 1954-3093

Éditeur

Centre d'études médiévales Saint-Germain d'Auxerre

Référence électronique

Dominique logna-Prat, « Socialiser la foi. Une esquisse de parcours ecclésial », Bulletin du centre d'études médiévales d'Auxerre | BUCEMA [En ligne], Hors-série $n^{\circ} 7$ | 2013, mis en ligne le 25 juillet 2013, consulté le 02 mars 2023. URL : http://journals.openedition.org/cem/13140 ; DOI : https://doi.org/ $10.4000 /$ cem. 13140

Ce document a été généré automatiquement le 2 mars 2023.

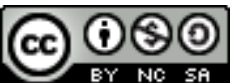

Creative Commons - Attribution - Pas d'Utilisation Commerciale - Partage dans les Mêmes Conditions 4.0 International - CC BY-NC-SA 4.0

https://creativecommons.org/licenses/by-nc-sa/4.0/ 


\title{
Socialiser la foi. Une esquisse de parcours ecclésial
}

\author{
Dominique logna-Prat
}

À la mémoire d'Edmond Ortigues

L'ecclésiologie en quête de "nouveaux horizons » se doit d'intégrer les grands thèmes de la théologie sacramentelle dans le périmètre des sciences sociales ${ }^{1}$. La présente étude voudrait contribuer à cette entreprise en abordant la question de la fides médiévale selon un angle d'attaque institutionnel. Mon «esquisse de parcours ecclésial » a pour objet de montrer non seulement comment la foi « socialise » dans un Occident latin où Église et société sont longtemps des termes co-extensifs, mais aussi comment un corps de croyances médiatisées peut « instituer ». Après de brefs rappels sur les origines pré-chrétiennes et chrétiennes du terme fides, je procèderai en trois temps, d'abord en traitant de la foi et de l'institution, puis de la foi de l'Église, enfin des tensions entre foi et croyance qui marquent le temps de sortie de la fides proprement médiévale.

\section{Foi et institution}

2 Fides (foi) et foedus (pacte, accord, alliance) ont une origine indo-européenne commune, beidth, d'où provient également la pistis grecque (confiance). Au sens actif, la foi signifie que l'on fait confiance, au sens passif que l'on inspire confiance ${ }^{2}$. Terme de relation, la fides romaine signifie la foi que le citoyen peut avoir en la cité, et la fiabilité morale et civique qu'il inspire. De façon complémentaire, le foedus traduit un engagement réciproque de confiance permettant de souder le corps civique, que fondent une même référence à un tiers instituant (les dieux), et une commune assurance de protection. En ce sens, fides et foedus sont des vertus " publiques », constitutives du " peuple » romain, sans qu'il soit besoin de postuler la moindre croyance : à Rome prévalent les rites, «dont le sens demeuraient implicite et qui n'imposaient pas d'autre croyance que l'observance ${ }^{3}$ ». 
3 La Bible et le monde juif ancien transmettent une autre conception de la fidélité. L'alliance de Dieu avec le peuple élu, qui est littéralement «son » peuple au possessif, est affaire de pacte (berith) et d'obligations résultant des engagements pris par les deux parties, dont l'Écriture fait mémoire. Dieu s'engage comme un suzerain le fait envers son vassal. À condition de respecter la lettre de l'engagement souscrit et d'être fidèle aux commandements divins, Israël se voit promettre la stabilité (aman) d'un "roc», promise à une dynastie royale, la maison de David (II Sam.7, 16), ainsi que l'intelligence, qui, selon Isaïe $(7,9)$ va de pair avec la stabilité.

4 Héritier de ces deux formes de pacte - le pacte civique romain et le pacte théocentrique de l'Ancien Testament -, le christianisme introduit une "croyance religieuse dans les liens de fidélité à la parole donnée : fidélité de Dieu à sa parole, et fidélité du chrétien à sa profession de foi ${ }^{4}$ ». La fides s'en trouve profondément transformée. Il ne s'agit plus d'être fidèle au Dieu de sa nation, ou d'adhérer par sa foi au pacte civique, mais de se défaire du "joug de la servitude » (la Loi) pour accéder à la "liberté de la foi », et d'entrer par conversion dans un cercle nouveau d'appartenance, la congrégation des disciples du Christ qu'est l'Ecclesia. La foi est ainsi une question de croyance et de témoignage, la chaîne des " témoins " permettant d'instituer une tradition. C'est autant une affaire individuelle qu'un problème de reconnaissance réciproque entre personnes d'une même communauté. D'où la nécessité d'actes partagés dans les rites, qui disent l'adhésion de chacun et de tous à la parole de Dieu.

\section{Des « choses humaines » à la « société des hommes »}

5 Aux origines chrétiennes, lorsque la congrégation des croyants n'en est encore qu'à un stade proto-institutionnel, Paul articule la "fidélité de Dieu " à la «société " ou « communion du Fils» (I Cor. 1,9). Il précise que cette communion est faite d'unité dans la diversité des charismes (I Cor. 12,7-11), chacun étant porteur d'une manifestation de l'Esprit, la foi parmi d'autres: parole de sagesse, science, don de guérir, miracles, prophétie, discernement des esprits, diversité des langues, don de les interpréter. Mais il classe les vertus constitutives de l'unité chrétienne en trois : foi, espérance et charité, tout en enseignant (I Cor. 13,13), que «la plus grande d'entre elles, c'est la charité ». Dans l'économie d'ensemble du premier christianisme, l'accent est ainsi mis d'emblée sur la caritas comme moteur de socialisation communielle. Sur cette base, toute la question est de faire la part de la construction institutionnelle encore à venir. Comme Yves Congar n'a cessé de le rappeler tout au long de son oeuvre, rien n'imposait a priori le passage de l'Église originellement conçue comme la congregatio fidelium au sens d'une fides simpliciter, d'une foi non historiquement, c'est-à-dire non " ecclésiastiquement " conditionnée, englobant tous les justes $a b$ Abel, à l'institution ecclésiale advenue ensuite dans le monde latin, sous la forme d'une Ecclesia quae modo romana dicitur, historiquement conditionnée, visible et substantielle, sous la forme d'une véritable monarchie spirituelle ${ }^{5}$.

6 C'est au titre de la congregatio fidelium comme rassemblement salutaire qu'Augustin (354-430), dans le De fide rerum quae non videntur, associe étroitement fides et caritas pour sortir l'humanité du chaos:

« Si on enlève la foi des choses humaines, comment ne pas s'attendre à les voir perturbées, et à l'horrible confusion qui doit s'ensuivre? Qui, en effet, peut être aimé d'un autre par une charité mutuelle, alors que cet amour même est invisible, si je ne dois pas croire ce que je ne vois pas? Toute amitié disparaitra parce qu'elle 
n'est qu'affaire d'amour mutuel. Qui pourra recevoir d'un autre, si rien n'est montré de son crédit? En outre, avec la disparition de l'amitié, impossible de maintenir en esprit (in animo) les liens du mariage, de la parenté et de l'alliance, parce que c'est en eux que, pour l'essentiel, se trouve l'harmonie de l'amitié. De fait, le conjoint ne peut aimer la conjointe d'un amour réciproque, s'il ne croit pas être aimé, parce qu'il ne peut pas voir cet amour. De même, ne désireront pas avoir d'enfants ceux qui ne pensent pas être aimés en retour. Que dire alors des autres liens (necessitudines) aux frères, sœurs, beaux-frères et beaux-parents, que dire des consanguins et des affins, si la charité est incertaine, la volonté mise en doute, et si l'engagement mutuel des enfants et des parents n'est pas acquitté... ${ }^{\circ}$ »

7 Il importe de noter qu'Augustin discute de la fides au plan des « choses humaines » afin de définir les «nécessités » qui font lien entre les hommes: le mariage, la parenté et l'alliance. Placée dans le champ sémantique de l'«amitié » et de la "charité », la fides est définie comme ce qui permet de croire à ce que l'on ne voit pas. Elle est un ressort de socialisation dans la mesure où ce qui unit demeure toujours invisible et quelque peu mystérieux. Être ensemble suppose une confiance active; c'est une manière de "pari salutaire », sans lequel aucune société n'est possible? . La foi est «autre » (fides aliena) ; la foi, c'est les autres.

8 L'enseignement d'Augustin est durablement reçu au Moyen Âge, mais il est l'objet d'inflexions significatives. À l'âge où l'Église devient, chez les clercs réformateurs, l'objet d'un discours propre sous la forme des premiers traités De Ecclesia, le cistercien anglais Baudouin de Ford, archevêque de Cantorbéry entre 1185 et 1190, compose un traité sur la foi, le De commendatione fidei, dont l'entame socio-ecclésiologique est frappante :

«Tous les pactes de la société humaine et tous les liens d'amitié, afin d'en assurer la stabilité, reposent sur l'intégrité de la foi et le maintien de ce qui a été établi. Tous les hommes veulent que la foi soit observée pour eux, même ceux qui refusent de l'observer. L'ami recherche la foi de l'ami, l'associé de l'associé, le maître de l'esclave, l'empereur du miles, le mari de la femme, lesquels vivent de ceux avec lesquels ils vivent. Sans foi, impossible d'administrer le gouvernement des biens, de répartir les offices et les services des hommes, ou d'apparier ceux qui s'aiment. Aucun royaume, aucune cité, aucune demeure particulière, aucun rassemblement petit ou grand d'hommes socialement organisés ne peuvent exister sans la foi ni se maintenir dans la félicité. Si tu enlèves la foi, le lien d'amour se rompt et tout traité d'amitié se dissout. Pas d'amour mutuel ni de paix quand on ne croit pas à la nécessité de l'engagement réciproque ${ }^{8}$.

Avec Baudouin, on passe des «choses humaines » augustiniennes à la "société des hommes ", du registre anthropologique de la parenté et de l'alliance aux " nécessités » sociologiques de penser la «dépendance", suivant l'un des sens du titre (de commendatione). "Vivre de ceux avec lesquels on vit " suppose de penser le lien, non plus au sein de la simple communauté des disciples du Christ, mais dans un monde social, royaume ou cité, où s'agencent des statuts différenciés selon des ordres de domination, telle la stratification maître/esclave et empereur/miles. Dès lors, la fides, combinée à la charitas et à la pax, assure l'« unité d'une société fraternelle ", parce qu'elle permet l'établissement d'un droit (ius humane societatis) ${ }^{9}$. Sans vouloir accentuer les contrastes à l'excès, il importe de bien noter que l'horizon socio-politique, entre Augustin et Baudouin de Ford, a profondément changé. Si la foi peut dire la norme sociale, c'est qu'elle s'est installée dans une institution, l'Église, qui entre les années 850 et 1150 , s'affirme progressivement comme la structure unique de gestion de la société chrétienne. 


\section{La foi dans l'Église}

\section{sermon de Boniface de Mayence (680-754) donne une bonne idée de la façon dont la foi} est devenue une vertu sociale d'Église :

«C'est à bon droit qu'il nous est demandé de vivre pieusement, d'aspirer aux biens éternels, et de procurer à chacun un lieu approprié à sa condition, de peur qu'il ne paraisse inoccupé ou d'une utilité moindre à sa place. Dans notre corps, il n'y a qu'une âme donneuse de vie, mais nombre de membres différents par leur fonction. De même, dans l'Église, il n'y a qu'une foi, qui doit être mise en œuvre par la charité, mais il y a diverses dignités ayant chacune leur propre service. Il y a un ordre des dirigeants, un autre des sujets, un ordre des riches, un autre des pauvres, un ordre des vieux, un autre des jeunes, chacun ayant sa propre marche à suivre comme chaque membre a sa fonction dans le corps. L'office des évêques est d'empêcher le mal et de corriger les violents tout en confortant ceux qui ont peur. L'honneur royal doit être source de crainte et de vénération de la part du peuple, parce qu' "il n'est de pouvoir que de Dieu" (Rom., 13,1). De même, il convient que tous les puissants et les grands soient fidèles au roi auquel ils sont attachés, et qu'ils soient humbles et miséricordieux ; il leur faut rendre une justice équitable et sans contrepartie, défendre les veuves, les orphelins et les pauvres, être soumis à leurs évêques, n'opprimer personne par la force, ne pas aspirer à des richesses indues, donner de leurs biens et non pas s'emparer de ceux d'autrui ${ }^{10}$.»

Ce sermon nous permet de comprendre dans quels termes un ordre anthropo-social a pu se définir dans l'Église, entre l'âge d'Augustin et l'époque carolingienne, par analogie entre, d'une part, l'âme et les différents membres du corps, et, d'autre part, la foi « mise en œuvre par la charité » et les diverses dignités et autres statuts qui organisent le corps social (dirigeants/sujets, riches/pauvres, vieux/jeunes). Un point notable de cet ordre anthropo-social est l'articulation nette que Boniface établit entre la foi (fides), «âme» de la machinerie sociale, et le régime des fidélités "attachées » au roi, la coalescence de la communion chrétienne et des relations de type vassalique s'exprimant dans un registre unique. Il convient d'autant plus d'insister sur le phénomène que l'affirmation de l'Église comme institution n'a pu se faire qu'au prix d'une "intelligente adaptation » à " une société féodale bien structurée, qu'elle s'est fixé pour but de dominer de l'intérieur $"{ }^{11}$. Le dominium généralisé de l'Église repose sur son insertion dans les rouages aristocratiques de contrôle de la terre et des hommes, et sur la maîtrise des liens constitutifs de l'ordre dominant. Princes et grands laïques se trouvent ainsi absorbés dans la fidélité et la vassalité de la papauté et de l'aristocratie d'Église, dont l'expression la plus achevée est la constitution d'une militia sancti Petri au XI ${ }^{\mathrm{e}}$ siècle ${ }^{12}$. Une simple consultation cursive des lettres de Grégoire VII (1073-1085), le pape de la réforme dite "grégorienne», persuade facilement de la confusion du politique et du religieux au titre de la « foi », les rapports au "vicaire de Pierre » en passe de devenir le «vicaire du Christ » obligeant à articuler subtilement fidélité et filiation dans la mesure où l'Église s'organise sur le modèle d'une grande famille spirituelle fondatrice de la souveraineté d'un Père monarque, en charge du spirituel comme du temporel, et à ce titre porteur de la tiare, à la fois mitre et couronne: mitra pro sacerdotio, corona pro regno ${ }^{13}$. On comprend, dès lors, que les questions de foi qui engagent les personnes puissent être du ressort des clercs, experts en matière théologico-juridique, comme le montre, entre autres exemples, la réponse que Fulbert de Chartres fournit au duc Guillaume V d'Aquitaine, en 1021, sur la nature

Bulletin du centre d'études médiévales d'Auxerre | BUCEMA, Hors-série $n^{\circ} 7$ | 2013 
et les fondements du serment (forma fidelitatis) ${ }^{14}$. D'où la congruence du vocabulaire clérical et du vocabulaire des institutions, qu'atteste l'explosion du champ sémantique de la «fidélité » au Moyen Âge, sous les formes diverses et complémentaires de la foi, qui se donne, qui se dit, qui se jure (fidedatio, fidedicere, fidefactum, fidemanus, fidejussio, fidejussor), et des modes "fiduciaires" du pacte et du serment (fidantia, fiducia, fidantiare: remise d'un gage; serment; promesse de sûreté, sauf-conduit, sauvegarde ${ }^{15}$. Quel que soit le domaine strict d'application de l'engagement, la foi est indistinctement une affaire de corps : fides corporalis des relations d'homme à homme, ou incorporation ecclésiale du fidèle.

Confusion des registres (civil/religieux) et congruence des vocabulaires (des clercs et des institutions) sont les traits d'une évolution lente afférente à la christianisation de la société et à l'ancrage de l'Église dans le siècle au cours de la première moitié du Moyen Âge. La prestation de fidélité au roi est attestée au plus tôt dans la première moitié du $\mathrm{VI}^{\mathrm{e}}$ siècle, aussi bien de la part des puissants laïques que des évêques ${ }^{16}$. Mais dans le monde "proto-féodal», toute la question est de savoir quels rapports établir entre traditions romano-chrétiennes et coutumes «barbares» (par exemple l'équivalence «leudes »/ »fidèles »), et quelle part faire, dans un contexte de christianisation active, aux coutumes nationales, qu'on ne manque pas de mentionner à l'époque carolingienne ${ }^{17}$. Dans la constitution de la féodalité classique, le serment de fidélité s'ajoute à la recommandation au plus tard au milieu du viII siècle ; le faciès chrétien est alors fortement affiché par référence à Dieu et aux saints et par attouchement des res sacrae $^{18}$. Un bon exemple de confusion des genres est fourni par le récit que donne Ermold le Noir (v. 790-v. 840), dans son Poème à Louis le Pieux, de la cérémonie conjointe du baptême et de l'entrée en vassalité du Danois Hérold et de son peuple. Invité par l'émissaire de l'empereur, l'archevêque de Reims Èbe, à venir en pays franc « rejoindre les vignes du Seigneur ", Hérold, son épouse et sa «maison » (domus) se rendent au palais-église d'Ingelheim, dans la vallée du Rhin. C'est là que se déroule un cérémonial complexe, autant laïque qu'ecclésiastique, calqué sur le rituel des assemblées carolingiennes ${ }^{19}$. Tout commence par un premier festin et un échange de discours, celui d'Hérold étant une véritable profession de foi de catéchumène ${ }^{20}$. On passe ensuite à l'église pour la cérémonie du baptême. Ermold se contente de décrire la fin de la cérémonie, la remise des habits blancs du baptisé à la sortie de l'onde, d'un peuple à l'autre et de haut en bas de la hiérarchie : de Louis à Hérold; de l'impératrice Judith à la reine; de Lothaire, fils et successeur désigné de Louis, au fils d'Hérold; des nobles francs aux nobles danois; du peuple franc au peuple danois ${ }^{21}$. L'assemblée fait ensuite retour au palais, où les festivités se poursuivent avec le don des produits de la terre franque et la remise de l'habit franc, exact décalque de la remise des habits baptismaux (de Louis à Hérold, de Judith à la reine, de Lothaire au fils d'Hérold). Le temps est alors venu, à l'appel des cloches, de gagner l'église où doit se dérouler la messe. Une fois la célébration eucharistique achevée, on revient au palais pour un «festin impérial ». Le lendemain, sur une île du Rhin, est organisée une partie de chasse, grand rituel laïque qui est l'occasion d'un autre type de mise en scène du pouvoir franc et d'une démonstration de la force souveraine ${ }^{22}$. Au retour, Louis, Hérold et leur suite se rendent à l'office du soir, puis gagnent le palais où l'empereur distribue rituellement le produit de la chasse. C'est au terme de ce long cérémonial, qui mêle intimement, dans les rituels et dans les lieux, l'ecclésiastique (baptême, messe et office dans l'église) et le laïque (accueil, remise de l'habit franc et festins au palais ; chasse dans l'île du cours du Rhin), qu'est scellée l'alliance des deux peuples à travers leurs princes. Après une 
dernière profession de foi, Hérold, placé aux pieds de Louis, fait hommage à l'empereur, qui, en retour, remet à son fidèle des domaines aux confins de l'Empire et les objets du culte (vases, vêtements et livres) destinés, par le medium de moines et de prêtres chargés d'accompagner les Danois, à fonder une nouvelle Église aux confins du monde franc. Fils spirituel et vassal, Hérold repart comme « adopté » par Louis le Pieux, et l'on peut se demander si le baptême et l'hommage décrits par Ermold le Noir ne recouvrent pas également, avec le rite de remise de l'habit franc, une adoption créatrice d'une filiation fictive devant permettre d'inscrire les Danois et leur prince dans la mouvance de l'Empire carolingien au titre de royaume vassal ${ }^{23}$.

\section{La foi de l'Église}

13 L'installation de la foi dans l'Église s'exprime par un manifeste recoupement des champs métaphoriques des deux termes. Les images de l'Église sont aussi celles de la foi, entre autres (l'énumération ne saurait être exhaustive) : cingulum, defensor, fervor, gubernaculum, munimentum, porta, portum, propugnacula, signaculum, speculum... Mais un pareil recoupement de champs suffit-il à expliquer ce qui est sans doute le trait d'évolution majeur de la fides tardo-antique et médiévale: l'émergence et le développement d'une "foi de l'Église»? Comment rendre compte du passage du " dans » au « de », de la topologie à l'appartenance, que marque l'expression au génitif (fides Ecclesiae)? Parce qu'en tant que corps, l'Église définit un espace vivifié par la caritas; Thomas d'Aquin (1124-1274) parle ainsi de la « foi formée » pour caractériser le cadre dans lequel peut s'exprimer « la foi vive qui agit par la charité », comme si la foi était une affaire de «forme » (forma, formula), la forme de l'Église, c'est-à-dire la norme de l'institution ${ }^{24}$.

\section{Médiation et garde du dogme}

14 L'abondant dossier de la "foi de l'Église ", qui a été patiemment rassemblé par MarieThérèse Nadeau, s'organise autour de deux valences du terme fides constamment intriquées, mais qu'il importe de distinguer pour la clarté de l'analyse : la foi objective (fides quae) - ce qui est cru, le contenu de la foi -, et la foi subjective (fides qua) l'attitude du croyant, le fait de croire, de faire confiance à Dieu ${ }^{25}$. L'une et l'autre de ces «fois» supposent la présence médiatrice de l'Église. La fides qua nécessite de défendre un contenu : canon et "règle de foi »; la fides quae, de gérer, de réguler une foi en actes, parce que, si la foi doit être agie, comme le souligne la parole de Jacques $(2,14:$ : Que sert-il à quelqu'un mes frères de dire qu'il a la foi s'il n'a pas les œuvres ? La foi peut-elle le sauver?»), encore faut-il qu'actes et acteurs soient encadrés, ne serait-ce que pour canaliser le volontarisme des fidèles et prévenir tout soupçon de pélagianisme ${ }^{26}$. Le plus souvent exprimée à la voie passive, la foi est ainsi une affaire d'adhésion croyante (confitetur) à ce que l'institution ecclésiale est capable de soutenir (roboretur) dans les différents champs des compétences cléricales: declaratur, praedicatur, dilatatur, diffunditur (homilétique et pastorale); designatur, signatur (exégèse) ; firmatur, manifestatur (liturgie et théologie sacramentelle).

Sur le versant de la fides quae, la foi de l'Église consiste, dès le $\mathrm{II}^{\mathrm{e}}$ siècle, à proclamer et à soutenir le dogme. Contre l'hérésie, qui est une foi erronée, il s'agit de définir la vraie doctrine et de s'y tenir au fil des développements de l'histoire des dogmes: le Credo de 
Nicée, les principaux décrets christologiques, la théologie trinitaire, la réalité de la chair et du sang dans l'Eucharistie, les effets salvifiques des sacrements, le champ de la dogmatique étant plastique et extensible au gré des besoins du magistère surtout à partir du moment - le dernier tiers $\mathrm{du} \mathrm{XI}^{\mathrm{e}}$ siècle - où la papauté proclame qu'est hérétique tout ce qu'elle déclare tel. Ce faisant, l'Église établit ses propres fondements : la foi évangélique et la tradition des apôtres que poursuivent les évêques, à la tête desquels se placent les pontifes romains, successeurs de Pierre et Paul; les Écritures et l'enseignement des Pères et des «docteurs", dont les commentaires sont venus vivifier et actualiser la foi de l'Église; l'ordre liturgique et sa conformité avec Rome, au point de traiter, à partir des années 1080, la notion d'ordo romanus comme un oxymore $^{27}$; ou de façon plus générale, comme on aime à s'y référer au $\mathrm{xI}^{\mathrm{e}}$ siècle, l'« antique foi de l'Église ", la "foi de la primitive Église», dont on soutient, depuis Grégoire le Grand (v. 540-604) au moins, qu'elle a vocation à l'universalité, la foi étant, dès les premiers Pères, conçue comme une "semence " ou une "bouture » fondatrice d'Églises ${ }^{28}$. Comme le dit Tertullien (v. 150-v. 230) , « dans chaque cité, ils fondèrent des Églises auxquelles, dès ce moment, les autres Églises empruntèrent la bouture de la foi et la semence de la doctrine, et l'empruntent tous les jours pour devenir elles-mêmes des Églises ", la tradition voyant dans le «ils " des propagateurs anonymes aussi bien les apôtres, que les princes chrétiens, ou simplement les prédicateurs, qui, au dire d'Alain de Lille (v. 1125/1130-1203), sont « les pieds de l'Église, par lesquels la foi de l'Église se propage et se diffuse $»^{29}$. La logique de cette dilatation explique qu'on puisse parler de la « foi de Chrétienté » au xIII e siècle, quand le prosélytisme chrétien véhiculé par le mythe de croisade a imposé l'emploi majuscule du terme « Chrétienté » dans une acception géo-politique idéalement référée aux dimensions de la Terre ${ }^{30}$.

16 Attachée aux vérités indéfectibles de la tradition, l'Église s'affirme très tôt - en Occident, avec le Contra haereticos d'Irénée de Lyon (v. 130-202) -, comme une instance apte à distinguer la vérité de l'erreur, la fides de la simple opinio et, surtout, de son exact contraire, l'infidelitas. Le tournant institutionnel marqué par la réforme de l'Église des $\mathrm{XI}^{\mathrm{e}}$-XII ${ }^{\mathrm{e}}$ siècles permet à la fois d'imposer le pouvoir médiateur des clercs au sein de la communion chrétienne, et de définir cette dernière à l'exclusion de tout corps étranger. Ad extra, les polémiques anti-hérétiques permettent de définir les contours de l'ordre ecclésial comme un périmètre étanche d'appartenance opposé aux diverses composantes (hérétiques, juifs, musulmans) d'une "hérésie générale» ${ }^{31}$. Ad intra, s'impose la nécessité d'une médiation fonctionnelle des clercs, fondement d'un véritable croire pour l'autre; Hugues de Saint-Victor (v. 1096-1141) soutient ainsi que " celui qui croit un croyant est dit croire sans inconvénient ${ }^{32}$ "; d'où la différentiation, courante au XIII ${ }^{\mathrm{e}}$ siècle, entre fides explicita et fides implicita, foi des doctes et foi des simples, à l'image de la distinction entre boves et asinae établie par les commentateurs du prologue du livre de Job, qui vulgarise la conception d'une fides majorum Ecclesiae ${ }^{33}$. Ce faisant, non seulement s'impose la notion d'une nécessaire médiation cléricale et savante, mais aussi l'idée que la foi s'acquiert (fides acquisita) par habitus, c'est-à-dire par immersion dans l'Église, même si «la foi gratuite » ou «infuse » comme don de Dieu reste toujours à l'horizon des réflexions théologiques ${ }^{34}$.

\section{Dynamiques sacramentelles}

C'est en contexte sacramentel que se forge, s'affermit et se développe l'essentiel du contenu attaché à la foi de l'Église. Comme le soutient une prière de la messe romaine 
attestée en Germanie au début du XI siècle - «Seigneur Jésus Christ, qui as dit à tes apôtres : je vous laisse la paix, je vous donne ma paix, ne regarde pas nos péchés mais la foi de ton Église»-, la foi est d'abord l'affaire de la communauté chrétienne rituellement assemblée ${ }^{35}$. La foi est fondée (firmatur) par les sacrements; elle se manifeste (manifestatur) dans les sacrements, spécialement l'Eucharistie, très tôt qualifiée, en concurrence avec le baptême, de «sacrement de la foi " (sacramentum fidei), et référée au "nouvel autel de la foi » érigé par le Christ, «nouveau roi et nouveau prêtre ${ }^{36}$. C'est dans cette logique que Wolber de Saint-Pantaléon (m. 1167), à l'âge des premières définitions du septénaire sacramentel, peut faire de la fides le contenant des sept sacrements rapportés au Christ, et qu'en plein $\mathrm{XvI}^{\mathrm{e}}$ siècle Bruegel l'Ancien (v. 1525-1569) se risque encore à placer sous l'enseigne de la fides un ensemble de sacrements mis en scène dans leur lieu d'effectuation, l'église [illustration], à la manière, un siècle plus tôt, de Roger Van der Weyden dans le Tryptique des sept sacrements ${ }^{37}$.

18 Mais c'est la question du baptême des enfants, ou pédobaptême, qui est appelée à marquer en profondeur la définition de la foi de l'Église. S'intéresser à la socialisation de la foi et à la force de ce qui fait lien (la fidélité, la confiance) dans une société de l'engagement personnel suppose de faire toute sa place au baptême, sacrement qui concentre l'essentiel de ce que le christianisme a inventé en matière de parenté spirituelle et de distinction anthropo-sociale entre la chair et l'esprit ${ }^{38}$. Pour qualifier le lien mystérieux et invisible qui unit les chrétiens, Augustin ne recourt pratiquement pas à la notion de fides Ecclesiae, lui préférant celle de fides catholica. Ce qui, au sein de la communauté, attache un fidèle à l'autre, ressortit pour lui de la fides aliena. Cette foi pour l'autre, dont nous avons vu la portée dans la gestion des "choses humaines", n'est pas encore confrontée à la question du baptême des enfants et du parrainage, une pratique qui ne s'impose que dans le haut Moyen Âge occidental, et qui devient l'objet de controverses déterminantes aux $\mathrm{XI}^{\mathrm{e}}$ et $\mathrm{XII}^{\mathrm{e}}$ siècles. C'est dans ce contexte que l'on passe, vers le milieu du XII ${ }^{e}$ siècle, de la fides aliena à la fides Ecclesiae, pour bien montrer, comme le font deux controversistes célèbres, Pierre le Vénérable (1092-1156) et Hugues d'Amiens (v. 1085-1164), qu'à travers les parents et les parrains, c'est l'Église qui s'engage pour l'enfant encore incapable de dire sa foi ${ }^{39}$. Les enfants, par l'intermédiaire de leurs garants, posent d'une façon particulièrement aiguë la question du tout ou rien qui donne un sens à la société chrétienne irriguée par la fides et la caritas : ou tout le monde est sauvé ou personne ne l'est. Pierre le Vénérable rapporte le pacte baptismal à la grâce qui circule entre l'homme et la femme au sein du couple chrétien, dans une union qui suppose de "donner sa foi ", tandis qu'Hugues d'Amiens discute du nécessaire engagement pour le jeune baptisé dans le cadre d'un traité De Ecclesia qui interroge globalement les mystères de l'Église. Sur le versant polémique de l'hérésie dite "albigeoise ", les actes du Concile de Lombers (1165) se réfèrent explicitement à l'institution du parrainage ${ }^{40}$ :

«Si l'on cherchait par la foi de qui les petits enfants sont sauvés, puisqu'ils ne possèdent pas par eux-mêmes la foi sans laquelle il est impossible de plaire à Dieu, nous disons que c'est par la foi de l'Église ou par la foi des parrains, de même que le paralytique fut guéri par la foi de ceux qui l'amenaient et le descendirent à travers les tuiles, et que le fils d'un officier royal et celui de la Cananéenne ont été sauvés au moment même où l'officier et la Cananéenne ont cru. Nous disons que le baptême doit être célébré dans l'église et par les ministres de l'Église, à moins que la nécessité ne presse. D'où cette parole du bienheureux Paul: “[Dieu] qui nous a rendus capables d'être serviteurs d'une nouvelle Alliance” (II Cor. 3,6 ) ${ }^{41}$.» 
19 À l'exemple des solidarités célébrées dans le Nouveau Testament (ici celles qui sauvent le paralytique [Matth.9,1-8], le fils d'un officier royal [Jean 4,46] et la fille de la Cananéenne [Matth. 15,21-28; Marc 7,24]), les enfants entament leur cheminement vers le salut grâce aux parrains, qui agissent comme des parents spirituels et représentent en quelque sorte la persona Ecclesiae, à une époque où s'impose précisément la notion juridique de persona ficta ou de persona repraesentata ${ }^{42}$. La mention finale des «ministres de l'Église » ajoute une note essentielle sur l'encadrement des clercs, car on ne saurait comparer les parrains, qui agissent in persona pueri, aux représentants de l'Église, qui agissent in persona Christi, sans lesquels le sacrement ne saurait être effectuét3. De fait, comme le défend un théologien contemporain, Pierre Lombard (v. 1095-1160), « la foi d'autrui ne vaut pas autant pour le petit que la foi propre pour l'adulte. Aux petits, en effet, la foi de l'Église ne suffit pas sans le sacrement ${ }^{44} »$. La foi de l'Église est ainsi autant une affaire "objective" (fides quae) relevant de l'encadrement (le contenu doctrinal défendu en contexte antihérétique) qu'un problème "subjectif » (fides qua) de gestion de l'autre, incapable ou empêché de dire sa foi. La fides aliena peut devenir la fides Ecclesiae parce que l'institution a désormais la capacité de croire efficacement pour l'autre - « capacité » et " efficacité » relevant de la sphère sacramentelle. D'où, sur la base du simple problème du pédobaptême, la rapide et notable extension du périmètre couvert par la foi de l'Église, avec, d'une part, la qualification de l'Église agissante Église " militante ", Église «triomphante », ou Église des saints, capables de mobiliser pour les autres le surplus dont ils n'ont pas besoin pour eux-mêmes -, et, d'autre part, la prise en charge de tout baptême par l'Église, pas simplement le baptême des enfants, mais aussi celui des adultes. On considère désormais que c'est la foi de tous les membres de l'Église qui «produit » le sacrement, et que la foi d'un seul, même adulte, n'y suffit plus, le « caractère baptismal », qui, selon Alexandre de Halès (v. 1185-1245), permet l'apposition du « caractère créé » par le « caractère incréé », étant " gravé dans la foi de l'Église » ${ }^{45}$.

20 Bien plus, au terme d'une notable maturation des conceptions sacramentelles au cours des $\mathrm{XII}^{\mathrm{e}}$ et XIII ${ }^{\mathrm{e}}$ siècles, ce n'est pas seulement le baptême qui relève de la foi de l'Église au titre de la fides aliena, mais l'ensemble des sacrements. Dans la discussion qu'il mène sur l'efficacité des sacrements, Thomas d'Aquin est un bon témoin de cette évolution. Pour lui, l'efficacité sacramentelle a trois sources: l'institution divine, la Passion du Christ, et la foi de l'Église " comme unissant l'instrument à l'agent principal », sans que la personne du ministre ne pose de problème particulier, car le sacrement peut fort bien être effectué par un hérétique, voire un fou ou un dément, s'il agit dans les " formes » de l'Église ${ }^{46}$. Le mariage lui-même, qui est sans doute le moins " cléricalisé " des sept sacrements - la question de ce qui «fait» le mariage étant l'objet de longs débats entre partisans du consentement des époux et ceux du pouvoir consécrateur de l'officiant qui procède à la junctio manuum -, n'échappe pas à la foi de l'Église avec la formulation, au XIII ${ }^{\mathrm{e}}$ siècle, de la notion de «mariage ratifié » par l'Église dans sa foi ${ }^{47}$.

\section{Le lieu de l'Église}

21 La «foi pour l'autre» (fides aliena) devenue la "foi de l'Église» au terme d'une remarquable évolution de la théologie sacramentelle aux XII et XIII ${ }^{e}$ siècles sur la base du baptême des enfants impose l'Église comme le lieu d'institution du croire par lequel doivent passer les sujets confessants, qui constituent collectivement la persona Ecclesiae. 
En ce sens, «l'autel de la foi », qui ouvre au fidèle la voie du sacrifice, s'inscrit, au Moyen Âge, nécessairement au sein de l'espace ecclésial, dans la mesure où le croire personnel relève d'un croire institué. D'où l'uniformisation des expressions confessionnelles à partir du moment où le confiteor - confession des péchés à la première personne, en public, le mercredi des cendres - fait son apparition dans les pontificaux (aux IX ${ }^{\mathrm{e}}$ et $\mathrm{x}^{\mathrm{e}}$ siècles), marquant le passage de la faute prise en compte pour elle-même, caractéristique du système de pénitence tarifée du haut Moyen Âge, au pénitent amené à dire en personne ses péchés, marque d'une pénitence individualisée ${ }^{48}$. Et c'est dans l'espace fixe et circonscrit offert par l'Église que le fidèle pénitent est invité à offrir son sacrifice. Sollicité sur le point de savoir s'il convenait de reconsacrer un autel qui a été bougé de place, Yves de Chartres (v. 1040-1116) propose un saisissant parallèle entre le fidèle et l'autel :

« ...de même que la foi, qui est le chef et le fondement de la sacrée religion, doit rester immobile dans la personne du croyant, de même pour l'autel visible, qui est la figure de la foi. Et de même que celui qui s'est écarté du fondement de la foi doit, par l'imposition des mains, être réconcilié au corps du Christ qu'est l'Église, de même la table d'autel, qui figure la foi, doit de nouveau être inaugurée (imbuenda) par les mystères sacrés, si elle a été bougée ${ }^{49}$. "

L'institutionnalisation du croire, qui ancre le désir du sujet confessant dans le devenir salvifique de l'Église, explique, par ailleurs, l'émergence de personnes de référence porteuses de la fides Ecclesiae, lesquelles sont autant de types de l'Église : la Cananéenne, le Centurion, Marthe, et surtout Pierre, dont la foi est, répète-t-on à l'envi, de " pierre » : une foi fondée sur le Christ, et une pierre/Pierre sur laquelle repose l'Église. Comme l'exprime un commentateur moderne de l'Évangile de Matthieu, Jean Hessel (1522-1556), porté par une abondante tradition médiévale :

«La louange de Pierre, louange de tous les chrétiens, est placée dans la puissance que Dieu, eu égard à la foi (intuitu fidei), lui a concédé ainsi qu'à tous ses successeurs. C'est ainsi que la pierre de la présente Église est à juste titre décrite comme le fondement de Pierre, à cause de la foi que le Christ a produit dans le vicariat qu'il lui a confié ainsi qu'à ses successeurs ${ }^{50}$.»

23 À l'image de ces types d'Église, le confessant/croyant habite la foi ; il vit de la foi de l'Église pour autant qu'il est dans l'église/Église. Inutile de rappeler ici le lent mouvement de monumentalisation de l'Église médiévale, au terme duquel il est impossible de penser le destin du sujet chrétien en communauté en dehors de la visibilité de l'institution de pierre/Pierre ${ }^{51}$. De fait, au chapitre de la foi de l'Église, les références monumentales ne manquent pas: Ambroise de Milan (v. 340-397) dénonce l'hérétique qui déforme l'habitation; Grégoire le Grand invite les fidèles à s'introduire dans l'édifice spirituel qu'est la « foi de la sainte Église »; Pierre le Vénérable défend la foi par la justification des murs d'église ; Bernard de Clairvaux (v. 1090-1153) évoque d'un même mouvement la foi de la mère Église et son manteau protecteur ; ou encore, un anonyme du XII ${ }^{e}$ siècle médite sur le " côté du Christ » comme " entrée » dans la foi de l'Église ${ }^{52}$. Sans surprise, la foi de l'Église s'inscrit dans la matrice chrétienne d'inclusion réciproque, qui oblige à penser le fidèle chrétien comme un «être dans ». Comme y insiste Augustin, à l'image des figures divines - «Je suis dans le Père, et le Père est en moi » (Jean, 14,11) -, « Dieu est au-dedans de nous », et il nous faut habiter en lui (Conf. 10,27), et de son côté, le Pseudo Denys l'Aréopagite soutient que « la foi divine établit les fidèles dans la vérité » et " établit en eux la vérité » ${ }^{53}$. C'est dans cette logique que se définit une véritable topologie du croire en régime de Chrétienté au cours du Moyen Âge. Selon une définition célèbre des Sentences de Pierre Lombard 
appelée à faire école - dont on connait désormais l'origine augustinienne -, l'actus fidei relève de trois façons de traiter grammaticalement Dieu: credere Deo (croire ce qu'il dit), credere Deum (croire qu'il est Dieu), credere in Deum (se donner à lui, s'incorporer à ses membres) ${ }^{54}$. Ces trois déclinaisons du croire sont indissociables : croire ce qu'il dit et croire en lui supposent et impliquent à la fois d'habiter en lui et d'en être possédé.

Économie du divin sur Terre, l'Église se voit naturellement comme le « lieu » du croire et l'instance propre à définir l'appartenance à la communauté de foi, faisant sienne la prescription de Paul à Timothée (I Tim. 6,20) : «garde bien le dépôt »; et c'est au titre de ce dépôt de la tradition qu'elle a pu "se former» (forma fidei), se constituer en instance normative, gardienne du dogme et des comportements, des vérités de foi et des façons d'être en société, bref s'instaurer publiquement en charge de l'« instruction des mœurs et de la foi » (instructio morum et fidei) ${ }^{55}$. On comprend dès lors que la foi ait pu devenir, en une conjonction des deux droits (utrumque ius), le domaine tant du juriste que du théologien; non seulement le fidèle ne peut manquer d'être un sujet de droit, mais l'évolution de la canonistique au cours du XII siècle sur la nature de l'hérésie et la qualification de son étrangeté en crime de lèse-majesté parvient paradoxalement à faire de l'hérétique "hors la loi» un sujet de droit tiré de son étrangeté pour intégrer l'ordre juridique propre à traiter les « errants dans la foi » ${ }^{56}$. À l'exemple de Théodose et de Justinien, qui, en faisant du christianisme une religion d'État, ont explicitement distingué les chrétiens des fous et des insensés, le prince chrétien médiéval se veut aussi, à sa manière (et les manières sont diverses selon le gradient théocratique du moment), le garant de la pureté et de l'unité de foi de ses sujets ${ }^{57}$. Comme l'a justement remarqué Laurent Mayali, cette pureté, affaire de foi, en vient à recouvrir, dans les années 1140 , le périmètre des " bonnes mœurs ", c'est-à-dire la conformité sociale, qui relève indistinctement du canonique et du civil, le terme foi et le vocabulaire de l'engagement confondant structurellement, dans la tradition médiévale, ce que nous considérons, en régime moderne, comme les registres dissociés du civil et de l'ecclésiastique ${ }^{58}$. C'est dans cette logique qu'à l'âge de la grande poussée théocratique de l'église romaine, dans le premier tiers du xiII ${ }^{e}$ siècle, on parvient à conjoindre sans difficulté le domaine du Credo et celui de la «bonne foi », garante de l'équité et de la force des contrats, comme l'attestent deux canons (1 et 41) du Concile œcuménique de Latran IV (1215). D'un autre côté, certains auteurs scolastiques réfléchissant sur la théorie des contrats, tel Pierre de Jean Olivi (1248/49-1298), ne manquent pas d'insister sur le fait que "par un vœu ou un serment [...] on s'oblige selon le droit divin», lequel ne doit pas être confondu avec cet autre tiers qu'est l'institution ecclésiale ${ }^{59}$. Ainsi, paradoxalement, la foi peut aussi permettre de limiter la pression de l'Église, en tant que force régulatrice de la plenitudo potestatis papale. Dans un passage de sa Summa de Ecclesia, Juan de Torquemada (1388-1468) rappelle que les églises, aussi bien que les personnes, les dignités, et les bénéfices relèvent de la «libre disposition et la plénitude du pouvoir» de Rome. Pour autant, en référence au commentaire de Thomas d'Aquin sur les Sentences, il met en valeur l'écart qui existe entre l'omnipotence divine et la "plénitude du pouvoir» des successeurs de Pierre, dans la mesure où l'Église consiste dans la foi et les sacrements, et qu'elle échappe de ce fait à la plenitudo potestatis rabaissée à une échelle "ministérielle " au regard de la toute-puissance de Dieu ${ }^{60}$. La foi hors d'atteinte de toute tentation théocratique ? La foi comme limite de l'institution? C'est une des voies de sortie exploitées par les réformateurs au XVI ${ }^{\mathrm{e}}$ siècle. 

véritable "trésor", un « coffret " (scrinium), où elle recueille et conserve les effusions de sang gratuites du Christ (qui n'a jamais péché) et les épanchements excessifs de ses saints, pour alléger les fidèles en peine, ni trop bons ni trop mauvais, incapables de s'en sortir par leurs œuvres propres ${ }^{61}$. Avec ce « trésor » d'Église, on passe en quelque sorte de la «foi pour l'autre » devenue «foi de l'Église» au geste pieux pour l'autre, du ressort de l'Église, qui marque une autre forme de prise en charge du croire par l'institution, puisque les perspectives et les modalités du salut relèvent du croire en l'institution: pas simplement l'appartenance à cette institution comme lieu du salut (credere in Ecclesiam : en être membre), mais aussi et surtout la conviction, la croyance que l'institution a, propriis verbis, le pouvoir de sauver, comme si le credere Ecclesiam (croire qu'elle est l'Église) ne pouvait que déboucher sur un credere Ecclesiae (croire ce qu'elle dit). C'est, d'une certaine manière, l'« Église de la foi » (fidei Ecclesia), qui, en un renversement rare mais significatif des termes (fides Ecclesiae/fidei Ecclesia), possède substantiellement la foi et son nécessaire complément d'œuvres propre à assurer le grand passage ouvert par le sacrifice gratuit du Christ vers l'Église triomphante ${ }^{62}$. Telle est justement l'architecture doctrinale que conteste plus tard Calvin (1509-1564), au titre de l'invisibilité de l'Église, quand il dit préférer le seul credere Ecclesiam, parce qu'on croit à ce qu'on ne voit pas ${ }^{63}$.

\section{Tensions et retournements}

L'histoire sociale de la foi esquissée ici - avec le passage de la fides aliena tardo-antique à la fides Ecclesiae systématisée en contexte sacramentel au cours du Moyen Âge, et l'emprise croissante d'une institution de droit - suppose de revenir, pour finir, à des questions de contenu, pour bien cerner les tensions constitutives de la relation entre foi et savoir.

\section{Un régime de la « double vérité »}

La foi est « une manière de posséder ce que l'on espère, un moyen de connaître des réalités qu'on ne voit pas ». Cette définition, tirée de l'Épître aux Hébreux $(11,1)$, est le pivot d'une réflexion de fond tout au long du Moyen Âge sur les rapports - d'exclusion ou de complémentarité -- entre foi reçue et savoir construit. À haute époque, la tension peut se dire en termes de contradictions originelles entre savoir antique païen et doctrine chrétienne, la question étant de savoir quelle place faire à l'une dans l'autre, et réciproquement. Avec la complexification progressive des « régimes de vérité » à la mesure de savoirs institutionnalisés, l'inflexion majeure que marque, à l'âge scolastique, l'émergence d'une autorité des maîtres universitaires, et la définition d'une architecture globale des sciences couronnée par la théologie et le droit, les vérités de foi sont soumises "à un examen dont les techniques relèvent d'un épistémologie générale ", qui suppose d'établir des "critères » d'appréciation propres à placer la foi dans le champ de l' "examen" (existimatio) et à maîtriser un régime de la «double vérité »: vérité de foi et vérité scientifique, le «et» pouvant se dire en termes d'articulation tout autant que de contradiction, et ainsi permettre de déterminer ad libitum le périmètre plus ou moins restreint des propositions accessibles à la seule foi ${ }^{64}$. Ce régime de la « double vérité » permet de dégager un incontestable espace de liberté

Bulletin du centre d'études médiévales d'Auxerre | BUCEMA, Hors-série nº 7| 2013 
d'auteur, lequel, par rapport aux autorités du passé, assume son commentaire, et qui, contre tous, serait-ce au risque de déclencher les foudres du magistère (la «double vérité » est condamnée par l'évêque de Paris, Étienne Tempier, en 1277), peut réaliser, pour le profit de tous, une " avancée autorisée ", c'est-à-dire reposant sur son autorité, l'auteur (actor, auctor) étant défini comme celui qui « augmente » (auctor est qui auget) ${ }^{65}$. Cette liberté est revendiquée et assumée par les maîtres de l'Université. Dans l'étude qu'elle a consacrée à l'autoconscience des maîtres universitaires, Catherine KönigPralong rappelle la distinction établie par Thomas d'Aquin entre "science" et "pouvoir» (scientia/potestas) : le pouvoir (celui des prélats par exemple) est attribué, tandis que la science s'acquiert librement ; c'est une acte de volonté personnelle, même si la fonction d'enseignement (la licentia docendi) suppose, elle, une sanction institutionnelle ${ }^{66}$.

\section{De la foi à la croyance}

Comme l'a bien noté Jean Wirth, le régime de la «double vérité » explique à moyen terme l'émergence du binôme foi/croyance. Le terme "croyance ", au sens de "tenir pour vrai », qui est attesté chez Nicole Oresme dans les années 1370, signe l'avènement d'un régime de l'«opinion ", laquelle induit diversité et pluralité, sans pour autant impliquer l'antonyme "incroyance ", qui ne s'impose que très tard au détriment de l'infidelitas ${ }^{67}$. Chez les penseurs modernes, ce binôme fait l'objet de deux traitements distincts. Le premier rassemble des penseurs de sensibilités philosophico-théologiques diverses; le Divinae Fidei Analysis seu De Fidei Christianae Resolutione d'Henry Holden (1655), dont l'influence est longue jusqu'à Newman, au XIX ${ }^{e}$ siècle, soutient la nécessité d'un medium institutionnalisé pour accéder aux vérités de foi ${ }^{68}$; de son côté, Thomas Hobbes, dans le Léviathan (1651), estime que les vérités de foi ne relèvent pas de la science mais de la croyance, et qu'au fond "nous avons foi seulement en des humains » (Is Faith in men only) dans lesquels nous plaçons notre confiance ${ }^{69}$. Dans le second, qui est la voie largement suivie par les Réformés aux XVI ${ }^{e}$ et XVII ${ }^{e}$ siècles, on se met en quête d'une foi rénovée, «à l'abri de la critique, au-delà du problème épistémologique " ${ }^{70}$; dans la charte de refondation critique que sont ses Loci communes, Melanchton (1497-1560) fait ainsi de la fides un strict équivalent de la pistis et de la fiducia, la vertu de la confiance en Dieu plus que le ressort d'une connaissance intellectuelle de Dieu particulièrement aléatoire à l'âge où diverses confessions chrétiennes honorent un même Dieu. Dans les termes de Pascal (1623-1662) : «La foi est un don de Dieu, ne croyez pas que nous disions que c'est un don de raisonnement ${ }^{71}$. » Dès lors, il n'y a plus de place pour une "foi de l'Église ", c'est-à-dire pour un régime dogmatique ecclésial de gestion du contenu et de contrôle des personnes croyantes, même si la catholicité issue du Concile de Trente parvient à fusionner profession de foi et serment d'obéissance au pape de tous ceux, universitaires et pasteurs, qui ont à charge la sauvegarde de la bonne doctrine ${ }^{72}$. Dans la critique de la notion d'Église qu'il mène dans La religion dans les limites de la simple raison (1793), Kant distingue soigneusement la «foi d'Église » de la «foi religieuse", les croyances (plurielles) ou "foi d'Église statutaire » de la " pure foi religieuse » ou religion universelle, c'est-à-dire la religion fondée sur la pure raison, qui marque l'accès à la « véritable Église » dont « la marque distinctive » est l'universalité - une "véritable Église », spirituelle, autrement qualifiée d' «État éthique (divin) sur terre », " général et public " ${ }^{73}$. À ce désenclavement de la foi moderne, privée de sa qualification «d'Église», il faut bien sûr associer la 
disjonction foi/œuvres revendiquée par la Réforme, qui fait fond sur la «foi seule » sans autre forme de médiation ou de recours au «trésor » de l'Église. Enfin, au terme de siècles de congruence, le vocabulaire religieux et le vocabulaire des institutions se dissocient à l'époque moderne. Certes, en régime absolutiste catholique, on soutient que le souverain est comptable de la conformité religieuse de ses sujets, qui sont " engagés " dans sa foi, au double sens du terme; de même, en terres réformées, on postule la cohérence confessionnelle des cadres politiques au nom de l'axiome cujus regio ejus religio. Pour autant, dans un monde où l'unité de foi est devenue problématique, s'impose une distinction plus ou moins ferme entre fidèle et sujet; comme le soutient Michel de l'Hospital, chancelier royal, devant les représentants catholiques et huguenots réunis à l'assemblée de Saint-Germain-en-Laye, en janvier 1562 , « le roi ne veut point que vous entriez en dispute quelle opinion est la meilleure; car il n'est pas ici question de constituenda religione, sed de constituenda republica; même l'excommunié ne cesse pas d'être citoyen ${ }^{74}$.

\section{L'institution de la croyance}

L'histoire ultérieure - qui est notre histoire en tant qu'histoire des champs de savoir à l'âge de la définition académique d'une epistémè fondatrice des sciences sociales -, montre toute la difficulté que pose le fait de dissocier la foi de l'institution. Comme l'a utilement rappelé Bruno Karsenti, pour le dernier Durkheim, celui des Formes élémentaires de la vie religieuse (1912), vivre socialement, c'est croire en commun; la communauté de foi est une communauté instituée, parce que "la croyance est instituée ", "la croyance est d'emblée prise dans l'institution " ${ }^{75}$. L'un des acteurs majeurs de la «querelle» de la théologie politique dans les années 1920-1930, Erik Peterson a soutenu dans des termes tranchés que «dans la foi, l'acte de croire ne se distingue pas de l'acte d'obéir, mais lui est lié intrinsèquement " ${ }^{76}$. La logique du dogme chrétien ne veut pas qu'on parle de Dieu, mais qu'on soit dans sa parole ${ }^{77}$. En ce sens, la théologie est une "topologie»; elle définit l'espace du dogme comme un périmètre d'adhésion et d'appartenance. La croyance est un fait d'institution, parce que, dans le long terme de la culture chrétienne, «la religion n'a pas d'autre moyen d'exister que d'unir l'esprit de piété et l'esprit de la communauté, la croyance et l'institution ${ }^{78}$ ». Mais encore faut-il s'entendre sur ce qu'on appelle l'« institution », et déterminer en quoi l'Église médiévale dont il a été question ici peut passer pour le modèle accompli de la «prise » dans la foi.

\section{NOTES}

1. Je remercie Frédéric Gabriel, Régine Le Jan et Alain Rauwel de leur lecture critique d'une première version de ce texte et de leurs indications bibliographiques.

2. E. Ortigues, « Foi », Encyclopaedia Universalis, 1996, 9, p. 579-586 [repris dans ID., La révélation et le droit, Paris, 2007, p. 213-238]. 
3. J. SCHEID, Les dieux, l'État et l'individu. Réflexions sur la religion civique à Rome, Paris, 2013 « Les livres du nouveau monde »), p. 214.

4. Ibid., p. 216-217.

5. Y. CONGAR, L'Église de saint Augustin à l'époque moderne, Paris, 1970 (« Histoire des dogmes », 20) ; ID., «Quatre noms de l'Église », dans ID., Écrits réformateurs, éd. J.-P. JossUA, Paris, 1995, p. 87-106 [publication initiale : 1961 et 1963 ].

6. Augustin, De fide rerum quae non videntur, c. 2, PL 40, col. 173 : «Si auferatur haec fides de rebus humanis, quis non attendat quanta earum perturbatio, et quam horrenda confusio subsequatur? Quis enim mutua charitate diligetur ab aliquo, cum sit invisibilis ipsa dilectio, si quod non video, credere non debeo ? Tota itaque perebit amicitia, quia non nisi mutuo amore constat. Quid enim ejus poterit ab aliquo recipere, si nihil ejus creditum fuerit exhiberi ? Porro amicitia pereunte, neque connubiorum neque cognationum et affinitatum vincula in animo servabuntur ; quia et in his utique amica consensio est. Non ergo conjugem conjux vicissim diligere poterit, quando se diligi, quia ipsam dilectionem non potest videre, non credit. Nec filios habere desiderabunt, quos vicissim sibi reddituros esse non credunt [...] Quid jam de caeteris necessitudinibus dicam, fratum, sororum, generorum atque socerum, et qualibet consanguinitate et affinitate junctorum, si charitas incerta, voluntasque suspecta est, et filiis parentum, et parentibus filiorum, dum benevolentia non redditur debita... »; pour une première approche d'ensemble de la fides chez Augustin : Augustinus-Lexikon, 2, col. 1333-1340 (E. TeSelle).

7. A. BOUREAU, « Foi », dans J. LE GOFF, J.-Cl. sCHMITT, dir., Dictionnaire raisonné de l'Occident médiéval, Paris, 1999, p. 422-434, qui renvoie à une autre œuvre d'Augustin, le De utilitate credidendi.

8. BAUDOIN DE FORD, De commendatione fidei, Prol., I, 1-2, éd. D. N. BELL, Turnhout, 1991 (CCCM, 99), p. 344-345: «Omnia federa societatis humane et amicitie leges, ut sua stabilitate constare possint, fidei sinceritate firmantur, et firmata seruantur. Omnes homines fidem sibi seruiri uolunt, etiam hii qui eam seruare nolunt. Fidem exquirit amicus ab amico, socius a socio, dominus a seruo, imperator a milite, maritus ab uxore : omnis qui uiuit ab eo cum quo uiuit. Sine fide nec gubernacula rerum ministrari, nec hominum officia uel ministeria dispensari, nec amantium paria ualent combinari. Non regna, non ciuitates, non singularum domicilia familiarium, nec quicumque cetus maiores uel minores hominum socialiter uiuentium, sine fide possunt constare, et in statu sue felicitatis permanere. Si fidem de medio tollas, uinculum dilectionis rumpetur, et omne fedus pacis dissoluetur. Non erunt qui se inuicem diligant, qui inter se pacem habeant, nisi sint qui sibi inuicem credant. »

9. Ibid., II (De fide ad proximum), p. 346, 1. 8.

10. BONIFACE DE MAYENCE (Winfrid), Sermo 9, Qui actus sint omni studio evitandi, et qui tota virium instantia sectandi, PL 89, col. 859-862 (col.859 D-860 C) : « Recte itaque vivere et pie et aeterna quaerere praecepit nobis, et unumquemque locum et conditionem suam diligenter procurare, ne vacuus appareat, vel minus utilis in loco suo. Una est enim corpori nostro anima, in qua vita consistit, sed multa sunt membra diversis distincta officiis. Sic in Ecclesia una est fides, quae per charitatem ubique operari debet, sed diversae dignitates proprias habentes ministrationes. Nam alius ordo praepositorum est, alius subditorum; alius divitum, alius pauperum; alius senum, alius juvenum; et unaquaeque persona habens sua propria praecepta, sicut unumquodque membrum habet suum proprium in corpore officium. Nam episcoporum officium est prava prohibere, pussilanimes consolaria protervos corripere. Deinde regius honor populis debet esse timori et venerationi, quia non est potestas nisi a Deo. Item, potentes et judices omnes qui regi adhaerent fideles sint oportet, et humiles, et misericordes, in aequitate judicare et non in muneribus, viduas et pupillos et pauperes defendere, episcopis suis subditos esse, neminem vi opprimere, non injustis divitiis inhiare, sua magis indigentibus dare quam aliena rapere "; cité et en partie traduit par J.-P. DeVRoEY, Puissants et misérables. Système social et monde paysan dans l'Europe des Francs (VI'-IXe siècles), Bruxelles, 2006, p. 35. 
11. P. TOUBERT, "Réforme grégorienne », dans Ph. LEVILLAIN, Dictionnaire historique de la papauté, Paris, 1994, p. 1432-1440 (p. 1434).

12. Sur la vassalité dans le périmètre immédiat de la souveraineté "étatique » romaine: S. CAROCCI, Vassali del papa. Potere pontificio, aristocrazie e città nello Stato della Chiesa (XII-XV sec.), Roma, 2010. Sur le problème général de la militia sancti Petri: C. ERDMANN, Die Entstehung des Kreuzugsgedankens, Stuttgart, 1935, p. 185-211.

13. Un exemple entre des centaines possibles: la lettre de Grégoire VII au comte Hubert, au clergé et à la poulation de Firmato, du 22 décembre 1074, auxquels le pape demande d'agir «ut appareat vos ingenuos et fideles esse matris Ecclesiae filios " (c'est moi qui souligne) : Das Register Gregors VII., éd. E. CASPAR, MGH, Epistolae selectae, München, 1990 (Berlin, 1920), II, 38, p. 174-175 (p. 175, 1).

14. FULBERT DE CHARTRES, Ep. 51, éd. F. BEHRENDS, Oxford, 1976, p. 90-93.

15. Sur la congruence des deux vocabulaires: A. GUERREAU, Le féodalisme, un horizon théorique, Paris, 1980, p. 183 ; J. WIRTH, « La naissance du concept de croyance », dans Id., Sainte Anne est une sorcière et autres essais, Genève, 2003 («Titre courant », 26), III, p. 113-176 (p. 123) [= Bibliothèque d'Humanisme et Renaissance, 45 (1983), p. 7-58] ; L. PEPPE, dir., Fides, fiducia, fidelitas. Studi di storia del diritto e di semantica storica, Roma, 2008 (je remercie R. M. DESSI de m'avoir signalé cet ouvrage).

16. F.-L. GANSHOF, Qu'est-ce que la féodalité, Paris, 1982 (Bruxelles, 1944) [commode mais vieilli]; S. REYNOLDS, Fiefs and vassals: the medieval evidence reinterpreted, Oxford/New York, 1994 ; É. Bournazel, J.-P. Poly, dir., Les féodalités, Paris, 1998 («Histoire générale des systèmes politiques »); Ph. DEPREUX, « Les Carolingiens et le serment », dans M.-F. AUZÉPY, G. SAINT-GUILLAIN, Oralité et lien social au Moyen Âge (Occident, Byzance, Islam) : parole donnée, foi jurée, serment, Paris, 2008, p. 63-80.

17. É. BOURNAZEL, J.-P. POLY, dir., Les féodalités, op. cit., p. 101.

18. F.-L. GANSHOF, Qu'est-ce que la féodalité, p. 57-58 (à propos du Capitulare missorum de 802).

19. J. L. NELSON, "The Lord's anointed and the people's choice: Carolingian royal ritual », dans Ead., Rituals of Royalty. Power and Ceremonial in Traditional Societies, éd. D.CANNADINE, S. PRICE, Cambridge, 1987, p. 137-180 (p. 166-172).

20. ERMOLD LE NOIR, In honorem Hludowici Pii, éd. et trad. E. FARRAL, Paris, 1932 ("Les classiques de l'histoire de France au Moyen Âge), v. 2198 s. ; présentation d'ensemble du dossier dans D. IOGNAPRAT, La Maison Dieu. Un histoire monumentale de l'Église, 800-1200, Paris, 2006, p. 144-146.

21. ERMOLD LE NOIR, In honorem Hludowici Pii, v. 2240 s.

22. Ibid., v. $2362 \mathrm{~s}$.

23. Je reprends ici une suggestion de Florian Mazel (communication orale).

24. THOMAS D'AQUIN, Somme de théologie, IIa IIae, q. 1, art. 9, sol. 3.

25. M.-Th. NADEAU, Foi de l'Église. Évolution et sens d'une formule, Paris, 1988 («Théologie historique ", 78).

26. Augustinus-Lexikon, 2, col. 1333-1340 (col. 1336).

27. A. RAUWEL, «La liturgie comme vecteur de la Réforme grégorienne ", dans La reforma gregoriana y su proyección en la Cristiandad Occidental? Siglos XI-XII, XXXII Semana de estudios medievales (Estella, 18-22 de julio 2005), Pamplona, 2006, p. 99-111 (p. 109).

28. Sur l'universalité de la foi chez Grégoire le Grand : M.-Th. NADEAU, Foi de l'Église, op. cit., p. 84.

29. TERTULLIEN, De praescriptione, 20,2,5: «Et perinde ecclesias apud unamquamque civitatem condiderent, a quibus traducem fidei et semina doctrinae ceterae exinde ecclesiae mutuatae sunt, et quotidie mutuantur ut ecclesiae fiant "; sur les princes chrétiens : M.-Th. NADEAU, Foi de l'Église, op. cit., p. 193 ; les prédicateurs, «pieds de l'Église»: ALAIN DE LILLE, Distinctiones dictionum theologicarum, PL 210, col. 839D-840A.

30. M.-Th. NADEAU, Foi de l'Église, op. cit., p. 223. 
31. P. JIMÉNEZ-SANCHEZ, « De la participation des cathares rhénans (1163) à la notion d'hérésie générale ", Heresis, 36-37 (2002), p. 201-218 (sur base, essentiellement, du De fide catholica d'Alain de Lille).

32. Hugues de Saint-Victor, De sacramentis christianae fidei, I, $\mathrm{x}, 3$, PL 176, col. 331D : « Nam et fides etiam est de fide qua creditur quod nescitur, quia scienti et credenti creditur. Ille enim qui credenti credit, non inconvenienter credere dicitur quod ille credit cui credit. »

33. J.-Cl. schmitT, «Du bon usage du Credo», dans A. Vauchez, dir., Faire croire. Modalités de la diffusion et de la réception des messages religieux $d u X^{e}{ }^{e}$ au XV $V^{e}$ siècle, École française de Rome, 1981 («Publications de l'École française de Rome », 51), p. 337-361 (p. 341) [repris dans ID., Le corps, les rites, les rêves, le temps. Essais d'anthropologie médiévale, Paris, 2001 ("Bibliothèque des Histoires »), p. 97-126 (p. 102)] ; J. Wirth, « La naissance du concept de croyance », art. cit., p. 127.

34. N. FAUCHER, «Prêter foi avec parcimonie. Le traitement scotiste de la foi acquise et de la foi infuse ", Conviction, croyance, foi, op. cit.

35. M.-Th. NADEAU, Foi de l'Église, op. cit., p. 104.

36. Fides Ecclesiae firmatur in sacramento : JULIEN DE TOLÈDE, In Nahum, PL 96, col. 729B-C (à propos du baptême) ; manifestatur: HILDEBERT DE LAVARDIN, Expositio missae, PL 171, col.1174B (à propos de l'Eucharistie) : «fides Ecclesiae in conficiendis corpore et sanguine domini manifestatur »; la notion de sacramentum fidei est fréquemment rapportée au corpus Christi et sanguinis chez Augustin et Paschase Radbert ; bon exemple de référence à l'altare fidei, dans RABAN MAUR, In Reg., III, 8, PL 109, col. 186C-D (= In Paralipomena, III, 7, ibid., col. 464B) : «Quia ergo holocausta et sacrificia omnia in altari typico Veteris Testamenti non potuerunt offerri, eo quod omnia ibi figuraliter fiebant, rex noster et sacerdos erexit novum altare fidei in Ecclesia catholica in quo pingua holocausta et sacrificia acceptabilia quotidie spiritaliter Deo offeruntur. »

37. WOLBER DE SAINT-PANTALÉON, In Cant., PL 195, col.1170A : «...[scriptus] signatus sigillis septem (Ap.5), hoc est septem sacramentis, quae fides Ecclesiae continet, nativitate Domini, circumcisione, baptismo, passione, resurrectione, ascensione, judicio futuro. " ; l'inscription qui accompagne la gravure ( Fides maxime a nobis conservanda est praecipue in religionem quia Deus prior et potentior est quam homo ») est tirée de Lactance, Epitome divinarum institutionum, CSEL, 19, p. 747, 1.5: «Fides quoque magna iustitia pars est : quae maxime a nobis, qui nomen fidei gerimus, conservanda est, praecipue... » (je tiens cette identification de S. Van der MeerenFerreri, que je remercie). Sur la gravure de Pierre Bruegel l'Ancien, qui s'intègre dans un ensemble consacré aux sept vertus: N. M. orenstein, éd., Pieter Bruegel the Elder. Drawings and Prints, New Haven/London, 2001, n64-77, p. 177-192 (p. 178-179), dont on donne ici la copie d'après l'original de son disciple Philips Galle; sur le Tryptique de Van der Weyden: D. IOGNAPRAT, La Maison Dieu, op. cit., p. 609-611.

38. Deux renvois essentiels sur la question : A. GUERREAU-JALABERT, « Spiritus et caritas. Le baptême dans la société médiévale », dans F. Héritier, É. COPET-ROUGIER, éd., La parenté spirituelle, Paris, 1996, p. 133-203 ; J. BASCHET, « Âme et corps dans la l'Occident médiéval : une dualité dynamique entre pluralité et dualisme », Archives de sciences sociales des religions, 112 (2000), p. 5-30.

39. D. IOGNA-PRAT, Ordonner et exclure. Cluny face à l'hérésie, au judaïsme et à l'islam, 1000-1150, Paris, 1998, p. 153-161;

40. Sur la mise en place et le développement de cette institution: J. H. LYNCH, Godparents and Kindship in Early Medieval Europe, Princeton, 1986; sur le Concile de Lombers, et la première qualification des dissidents comme des «bons hommes » : J.-L. BIGET, Hérésie et inquisition dans le Midi de la France, Paris, 2007 ( Les médiévistes français », 8), p. 41 et p. 153-154..

41. MANSI, Sacrorum conciliorum nova et amplissima collectio, XXII, Ann. 1166-1225, col.157-168 (col. 162D) : «Si autem queratur, cujus fide salvantur infantes, cum ipsi fidem non habeant, sine qua impossibile est Deo placere: dicimus quia fide ecclesiae, vel fide patrinorum, sicut paralyticus est curatus fide offerentium, et per tegulas submittentium eum; et filius reguli, et 
filia Chananaeae salvati sunt eadem hora qua regulus et Chananaea crediderunt. Dicimus enim, quod baptisma debet celebrari in ecclesia, et per ministros ecclesiae, nisi necessitas urgeat. Unde dicit beatus Paulus "Qui idoneos nos fecit ministros Novi Testamenti" "; trad. partielle M.Th. NADEAU, Foi de l'Église, op. cit., p. 139. Autre témoin contemporain de la controverse : Guillaume le Moine, Contre Henri schismatique et hérétique, 6, 6, éd. M. ZERNER, Paris, 2011 ("Sources chrétiennes ", 541), p. 208, et l'anonyme Contre les hérétiques et les schismatiques, 4, 10, ibid., p. 250.

42. P. MICHAUD-QUANTIN, Universitas. Expressions du mouvement communautaire dans le Moyen Âge latin, Paris, 1970 (« L'Église et l'État au Moyen Âge », 13), p. 201-208.

43. B. MARLIANGEIAS, Clés pour une théologie du ministère : in persona Christi, in persona Ecclesiae, Paris, 1978 ("Théologie historique », 51), p. 108 ; A. RAUWEL, Expositio missae. Essai sur le commentaire du Canon de la messe dans la tradition monastique et scolastique, Thèse de doctorat, Université de Bourgogne (Dijon), 2002, t. II, p. 223-224.

44. PIERRE LOMBARD, Sententiae, IV, d. 4, cap. 4, § 12, Grottaferrata, 1981, p. 259, 1. 9-11: « Nec tantum valet fides aliena parvulo, quantum propria adulto. Parvulis enim non sufficit fides Ecclesiae sine sacramento. »

45. ALEXANDRE DE HALÈs, IV Sent., dist. I, n ${ }^{\circ} 2^{\mathrm{e}}$, éd. Quaracchi, Florence, 1958, p. 107 ; cité par M.Th. NADEAU, Foi de l'Église, op. cit., p. 224.

46. THOMAS D’AQUIN, IV Sent., dist. I, q. I, art. IV, qua 3, réponse, Paris, 1947, p. 36 ; cité par M.Th. NADEAU, Foi de l'Église, op. cit., p. 288.

47. M.-Th. NADEAU, Foi de l'Église, op. cit., p. 226-228.

48. J.A. JUNGMANN, Die lateinischen Bußriten in ihrer geschichtlichen Entwicklung, Innsbruck, 1932 («Forschungen zur Geschichte des innerkirchlichen Lebens », 3/4), p. 189-190.

49. YVES DE CHARTRES, Ep. 72, PL 162, col. 92A-B : «...sicut fides, quae caput et fundamentum est sacrae religionis, immobilis debet manere in credente, sic visibile altare, quod figuram gerit fidei debet manere immobile. Et sicut a fundamento fidei, si quis motus fuerit per manus impositionem corpori Christi, quod est Ecclesia, reconciliandus est, sic mensa altaris fidei typum gerens, si mota fuerit, iterum sacris mysteriis imbuenda est. »

50. J. HESSEL, In Mattheum, Louvain, 1572, $\mathrm{f}^{\circ} 119 \mathrm{v}$. : « [...] Petrus omnium christianorum laus igitur Petri in eo sita est, quod Deus intuitu fidei hanc potestatem ipse contulerit, atque omnibus eius successoribus [...] ita ut etiam praesentis Ecclesiae petra, et fundamentum merito dictatur Petrus, propter fidem quae Christum ad vicariatum suum ei, et omnibus eius successoribus committendum provocavit »; cité par F. GABRIEL, «Pouvoir de l'Église et personne du pape : toute

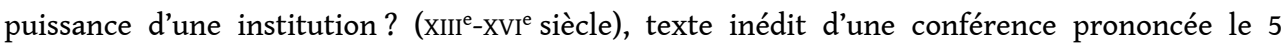
février 2013, à l'ÉPHE, séminaire d'O. Boulnois, Dominium II : Liberté et pacte social.

51. D. IOGNA-PRAT, La Maison Dieu, op. cit.

52. Références à tous ces textes dans M.-Th. NADEAU, Foi de l'Église, op. cit., respectivement p. 53 (Ambroise), 86 (Grégoire le Grand), 121 (Pierre le Vénérable), 130 (Bernard de Clairvaux), et 177 (anonyme du XII ${ }^{\mathrm{e}}$ siècle, qui dépend d'Augustin, In Ioh., § 2-3, PL 35, col. 1953-1954 : méditation sur l'ouverture du côté de Christ, véritable acte d'engendrement de la sacramentalité de l'Église dans le sang et l'eau du Crucifié).

53. PSEUdo denYS L'ARÉOPAGITE, Noms divins, VII, 4, PG 3, col. 872C ; cité par O. BOULNOIS, «Les trois dimensions de la foi. Le concept de foi selon quelques théologiens médiévaux (XII ${ }^{\mathrm{e}}-\mathrm{XIV}^{\mathrm{e}}$ siècles) ", dans Conviction, croyance, foi, op. cit.

54. PIERRE LOMBARD, Sententiae, III, d. 23, cap. 4, § 1, Grottaferrata, 1981, p. 143, 1. 13-18 : « Aliud est enim credere in Deum, aliud credere Deo, aliud credere Deum. Credere Deo est credere vera esse quae loquitur: quod et mali faciunt; et nos credimus homini, sed non in hominem. Credere Deum, est credere quod ipse sit Deus : quod etiam mali faciunt. Credere in Deum, est credendo amare, credendo in eum ire, credendo ei adhaerere et eius membris incorporari »; comme l'a montré I. BOCHET, «Les définitions augustiniennes de la fides: au croisement des traditions 
philosophiques et de l'exégèse biblique ", dans Conviction, croyance, foi, op. cit., la formule est inspirée d'un sermon d'Augustin: F. DOLBEAU, Augustin d'Hippone. Vingt-six sermons au peuple d'Afrique, Paris, 1996, sermon 19, 5, p. 159.

55. Pour reprendre la définition de la prédication donnée par ALAIN DE LILLE, Summa de arte praedicatoria, PL 210, col.111C : «...manifesta et publica instructio morum et fidei, informationi humanum deserviens, ex ratione semita, et auctoritatum fonte proveniens. »

56. M. BASSANO, « Normativer l'anormal : l'esprit juridique des sommes anti-Vaudois de la fin du $\mathrm{XII}^{\mathrm{e}}$ siècle ", dans L'Ordre chrétien médiéval entre le droit et la foi, Revue d'histoire des religions, 228/4 (2011), p. 541-566 (p. 548-549) ; la qualification « errants dans la foi » (aberrantes in fide) est tirée de la fameuse Bulle Vergentis in senium d'Innocent III (1199), qui qualifie pour le première fois l'hérésie comme crime de lèse-majesté.

57. Édit de Thessalonique, Cunctos populos, Cod.1.1.1. ; cité par L. Mayali (voir note suivante).

58. L. MAYALI, «De la raison à la foi : l'entrée du droit en religion », dans L'Ordre chrétien médiéval entre le droit et la foi, p. 475-482 (p. 479-480).

59. PIERRE DE JEAN OLIVI, Traité des contrats, III (Des restitutions), 94, éd. et trad. S. PIRON, Paris, 2012 («Bibliothèque scolastique »), p. 318-319.

60. J. DE TORquemadA, Summa de Ecclesia, II, 36, Salamanque, 1560, p. 252-254 ; cité par F. GABRIEL, "Pouvoir de l'Église et personne du pape », art. cit.

61. La définition canonique $d u$ «trésor de l'Église » est donnée par HENRI DE SUSE (Hostiensis), Summa aurea, Venise, 1570, V, de remissionibus, § 6 ; V. PASCHE, « Trésor de l'Église », dans A. VAUCHEZ, dir., Dictionnaire encyclopédique du Moyen Âge, II, Paris, 1997, p. 1536.

62. La concordance de la Patrologia latina ne fournit que dix entrées à fidei Ecclesia; les deux principales font logiquement références au Christ: RUPERT DE DEUTZ, In Is., PL 167, col. 1346B : «Domus majestatis Domini sancta catholicae fidei Ecclesia est, altare autem ejus placabile, ipse Christus est »; Gerhoh de Reichersberg, In Ps. 26, PL 193, col. 1185D : « non nisi in una unius fidei Ecclesia Christus regnat. "

63. CALVIN, Institution de la religion chrétienne, éd. M. DE VÉDRINES, P. WELLS, Aix-en-Provence/ Charols, 2009, IV,i,2, p. 946-947 ; A. GANOCZY, Calvin théologien de l'Église et du ministère, Paris, 1964 («Unam Sanctam », 48), p. 193.

64. A. BOUREAU, « Foi », p. 429 ; J. WIRTH, « La naissance du concept de croyance », art. cit., p. 133 ; P. BERMON, «Scepticisme et fidéisme chez Robert Holcot », dans Conviction, croyance, foi, op. cit.

65. G. LECLERC, Histoire de l'autorité. L'assignation des énoncés culturels et la généalogie de la croyance, Paris, 1996, chap.4.; M. ZIMMERMANN, dir., Auctor et auctoritas. Invention et conformisme dans l'écriture médiévale, Paris, 2001 ("Mémoires et documents de l'École des chartes », 59).

66. C. KÖNIG-PRALONG, Le bon usage des savoirs. Scolastique, philosophie et politique culturelle, Paris, 2011, p. 64-65.

67. N. ORESME, Éthiques, 231 : «Ils eurent tel croiance par un signe ou argument qui n'est pas suffisant »; sur la question de l'« incroyance » du Moyen Âge et à l'Époque moderne : D. WELTECKE, "Der Narr spricht : es ist kein Gott». Atheismus, Unglauben und Glaubenszweifel vom 12. Jahrhundert bis zur Neuzeit, Frankfurt am Main/New York, 2010, spéc. p. 257-295.

68. J. LE BRUN, "L'institution dans la théologie de Henry Holden (1596-1662) », dans Id., La jouissance et le trouble. Recherches sur la littérature chrétienne de l'Âge classique, Genève, 2004 («Titre courant ", 32), chap. VII, p. 161-174 [ ${ }^{\circ}$ première parution : Recherches de sciences religieuses, 71/2 (1983), p. 191-202].

69. THOMAS hOBBES, Léviathan, 7 (« Des fins des discours»), trad. G. MAIRET, Paris, 2000 («Folio essais »), p. 141-146 (p. 146). Je remercie E. Coccia de cette suggestion.

70. J. WIRTH, «La naissance du concept de croyance », art. cit., p. 153-154.

71. PASCAL, Pensées, éd. Ph. SELliER, Paris, 2003 (« Agora, les classiques »), p. 366. 
72. P. PRODI, Il sacramento del potere. Il giuramento politico nella storia costituzionale dell'Occidente, Bologna, 1992 (« Annali dell'Istituto storico italo-germanico, Monografia », 15), p. 311-320.

73. KANT, La religion dans les limites de la simple raison, III, 7, trad. J. GIBELIN, M. NAAR, Paris, 2010 («Bibliothèque des textes philosophiques »), p. 200 et 209-210.

74. CEuvres de Michel de l'Hospital, éd. M. DUfEY, Paris, 1826, I, p. 451 ; cité par J. LECLER, Histoire de la tolérance en France au siècle de la Réforme, Paris, 1994 [1955] («Bibliothèque de L'Évolution de l'humanité »), p. 454.

75. B. KARSENTI, «Structuralisme et religion », dans O. REMAUD, J.-F. SCHAUB, I. THIREAU, dir., Faire des sciences sociales : comparer, Paris, 2012, p. 61-93.

76. E. PETERSON, «Qu'est-ce que la théologie?» (1925), dans Id., Le monothéisme: un problème politique, trad. franç, Paris, 2007 [Leipzig, 1935]; cité et analysé par B. KARSENTI, « Autorité et théologie. Peterson et la définition chrétienne du dogme », Archives de philosophie, 74/1 (2011), p. 149-168 (p. 155).

77. Ibid., p. 157.

78. E. ORTIGUES, Le monothéisme. La Bible et les philosophes, Paris, 1999 («Optiques Philosophie »), p. 6 .

INDEX

Mots-clés : croyance, dogme, institution, foi, lien social

\section{AUTEUR}

\section{DOMINIQUE IOGNA-PRAT}

CNRS/EHESS - Centre interdisciplinaire des faits religieux (UMR 8216) 